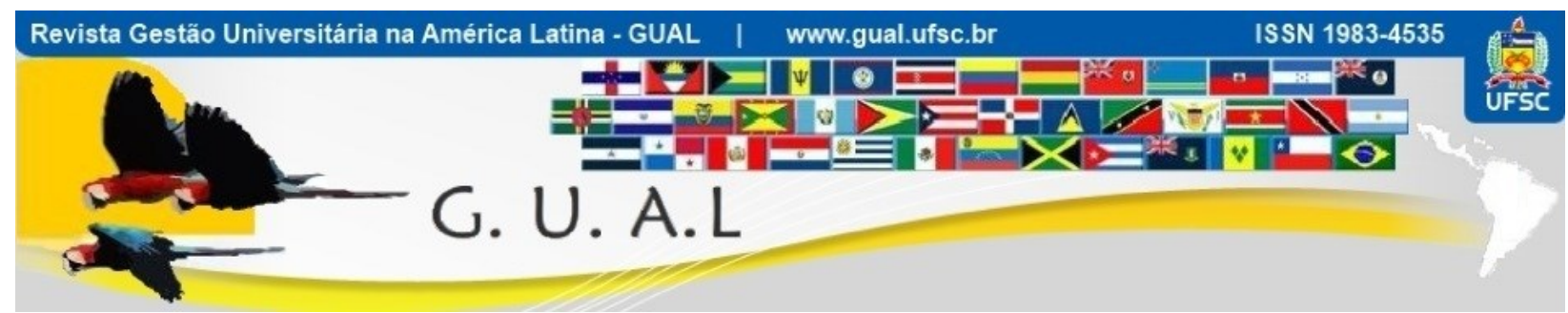

DOI: http://dx.doi.org/10.5007/1983-4535.2014v7n3p268

\title{
ANÁLISE DO PROCESSO DE IMPLANTAÇÃO DO BALANCED SCORECARD (BSC) EM UMA INSTITUIÇÃO DE ENSINO SUPERIOR
}

\section{REVIEW OF THE IMPLEMENTATION OF THE BALANCED SCORECARD (BSC) IN A HIGHER EDUCATION INSTITUTION}

Josilene Martins Rocha, Especialista Pontifícia Universidade Católica do Rio Grande do Sul - PUCRS josilene.rocha@pucrs.br

Alam de Oliveira Casartelli, Doutor Pontifícia Universidade Católica do Rio Grande do Sul - PUCRS alam.casartelli@pucrs.br

Recebido em 04/fevereiro/2013

Aprovado em 08/maio/2014

Sistema de Avaliação: Double Blind Review

Esta obra está sob uma Licença Creative Commons Atribuição-Uso. 


\title{
RESUMO
}

O presente trabalho tem por objetivo avaliar os fatores críticos para a implantação da metodologia de balanced scorecard (BSC) em uma instituição de ensino superior (IES). O método utilizado consistiu em uma pesquisa exploratória, por meio de entrevistas em profundidade realizadas com oito gestores que tiveram atuação importante no processo de implantação do BSC. A análise de dados iniciou com a transcrição das entrevistas e posterior avaliação do conteúdo, sendo destacado como positivo o reconhecimento da importância do planejamento estratégico (PE) para as IES; a existência de um foco estratégico comum; a definição de prioridades institucionais abrangentes; a criação de uma equipe de implantação capaz de disseminar a metodologia do BSC; possuir uma ferramenta da tecnologia da informação para apoiar o processo e contar com a participação ativa da alta administração. Além disso, foram apontados como desafios a maior apropriação da ferramenta pelos usuários; a integração do sistema de BSC aos demais utilizados pela Universidade e o aprofundamento da cultura de gestão estratégica de longo prazo.

Palavras-chaves: Balanced scorecard. Planejamento estratégico. Ensino superior.

\begin{abstract}
This study aims to evaluate the critical factors for the implementation of the methodology of Balanced Scorecard (BSC) in a higher education institution. The method used consisted of an exploratory research through in-depth interviews with eight managers who played an important role in the process of implementing the BSC. Data analysis began with transcription of the interviews and subsequent review of the content, being highlighted as positives the recognition of the importance of strategic planning for a higher education institution; the existence of a common strategic direction; the definition of comprehensive institutional priorities; the creation of a deployment team able to spread the BSC methodology; owning an information technology tool to support the process and rely the active participation of senior management. Moreover, the integration of the BSC system to others used by the University and the deepening of the long-term strategic management culture, were identified as challenges to greater ownership by the users of the tool.
\end{abstract}

Keywords: Balanced scorecard. Strategic planning. Higher education institution. 


\section{INTRODUÇÃO}

Os profissionais da área de gestão têm uma constante preocupação em aperfeiçoar ou desenvolver metodologias que sejam capazes de responder as mudanças ocorridas na sociedade e na economia. Com esse intuito é que Kaplan e Norton propuseram, no início dos anos 90, a metodologia denominada balanced scorecard (BSC). Essa trouxe como inovação a possibilidade de acompanhar as ações, projetos, objetivos e estratégias através de indicadores de desempenho alinhados à missão e visão da empresa, e distribuídos nas perspectivas financeira, cliente, processos internos e aprendizado e crescimento.

Inicialmente, o BSC foi utilizado pela indústria e pelo comércio, que passaram a acompanhar os resultados dos seus indicadores através de metas pré-estabelecidas, de modo a garantir o cumprimento dos objetivos futuros. O sucesso obtido com a utilização dessa metodologia estimulou o uso do BSC em outros setores, como o do ensino superior.

O setor de ensino superior está inserido em um ambiente de constante inovação e busca pela qualidade. Essa busca tem possibilitado a incorporação do BSC à gestão acadêmica, que por sua vez, tem procurado redefinir as suas estratégias diante da dinâmica do mercado atual. Mudanças como a ascensão econômica da classe $\mathrm{C}$, as novas formas de fomento (Programa Universidade Para Todos - PROUNI e Fundo de Financiamento Estudantil - FIES), as inovações tecnológicas e o aumento do número de instituições de ensino superior (IES) têm impactado significativamente nesse setor.

A ascensão econômica da classe $\mathrm{C}$ transformou o padrão de consumo dos seus jovens. Segundo Souza (2012), muitos desses jovens passaram a visualizar a conclusão de um curso superior como algo possível e capaz de transformar a sua realidade. Esse jovem se compromete a gastar pensando no futuro, tendo consciência de que a formação superior é uma facilitadora da sua entrada no mercado de trabalho. Além disso, estão buscando mudar a sua condição social, sendo que grande parte é a primeira geração da família a entrar na faculdade. Desses, $75 \%$ definem a carreira não pela vocação, mas pela oportunidade de futuro, sendo que ao escolherem a IES, levam em consideração a proximidade da faculdade, o valor da mensalidade e os cursos oferecidos.

O governo, por sua vez, desenvolveu novas formas de fomento (PROUNI e FIES) que possuem um papel fundamental para o aumento no número de universitários no Brasil. Ambos são programas de inserção social, que buscam fornecer bolsas de estudos ou financiamento aos jovens de baixa renda. O PROUNI foi desenvolvido pelo Governo Federal 
com a finalidade de oferecer bolsa de graduação para estudantes carentes em IES privadas. O FIES consiste em um programa do Ministério da Educação destinado ao financiamento da graduação em instituições não gratuitas.

As inovações tecnológicas também impactam na educação superior. A própria banda larga é uma facilitadora desse processo, pois amplia oportunidades de informação e comunicação, sendo um dos fatores responsáveis pelo aumento da oferta de cursos de ensino a distância (EAD). Além disso, todos os aparatos tecnológicos desenvolvidos nos últimos anos e a entrada de alunos nativos digitais no ensino superior deram origem a novas formas de difusão do conhecimento e do aprendizado.

Diante dessa nova realidade, ocorreu uma proliferação do número de IES no país. $\mathrm{Na}$ década de 90, foi permitida a atuação de instituições com fins lucrativos no setor da educação superior. Posteriormente, iniciou a entrada de capital internacional e o crescimento dos grupos educacionais, sendo que muitas dessas novas instituições têm como estratégia o posicionamento pelo preço. Além disso, as IES passaram a fazer movimentos mercadológicos, aumentaram as suas estruturas físicas, o número de cursos e investido na divulgação de suas vantagens competitivas.

Inseridas nesse cenário, as IES precisam corresponder às exigências do mercado interno e externo, além de se manterem alinhadas às diretrizes que regem o ensino superior. Frente a isso, torna-se ainda mais importante a necessidade dessas instituições de terem clareza quanto a sua visão, missão, estratégias e metas.

Dessa forma, as IES encontram nos processos de gestão a possibilidade de melhoria e crescimento. Com isso, a adoção de metodologias que são utilizadas com eficiência em outros setores da economia, tem se mostrado um desafio necessário no setor da educação superior. Dentro dessa situação, o BSC se constitui um importante mecanismo para a qualificação da gestão nas IES, que passaram a adotá-lo como metodologia de gestão.

Com os objetivos de identificar os fatores de sucesso na implantação dessa metodologia, as características que mais podem contribuir para a disseminação da nova forma de gestão em uma IES, bem como as maiores dificuldades encontradas pelos gestores no momento da implantação, é que se questionou: quais os fatores críticos na implantação do balanced scorecard em uma instituição de ensino superior?

Para tanto, se formulou um roteiro semiestruturado com os fatores críticos para implantação do BSC apresentados por Kaplan e Norton (2000), Prieto et al (2006) e Rocha e 
Lavarda (2011). Esse roteiro serviu de base para as entrevistas em profundidade que foram realizadas com oito gestores da instituição pesquisada.

Essa pesquisa possui caráter qualitativo e, por esse motivo, tem-se a intenção de gerar dados secundários para futuras análises. O que permitirá compreender melhor o processo de implantação de BSC em IES e adotar medidas para corrigir possíveis falhas e prevenir dificuldades em futuras implantações

\section{FUNDAMENTAÇÃO TEÓRICA}

\subsection{PLANEJAMENTO ESTRATÉGICO E BALANCED SCORECARD}

O planejamento estratégico (PE) é definido por Oliveira (2007) como uma metodologia administrativa capaz de estabelecer a direção a ser seguida pela empresa. Para Braga e Monteiro (2005) o PE deve produzir respostas consistentes para três questões fundamentais: Onde estamos? Aonde queremos chegar? Como vamos chegar? Além de obterem essas repostas, as empresas poderão, através do PE, desenvolver ações que visem conhecer e potencializar os seus pontos fortes, conhecer e eliminar ou modificar as suas fraquezas, conhecer e aproveitar as oportunidades externas assim como evitar as ameaças.

Segundo Oliveira (2007), a implantação do PE deve passar por seis fases que consistem no delineamento das grandes questões estratégica da empresa, ou seja, da sua visão; no estabelecimento da amplitude e da abordagem dos negócios através da definição da missão, propósitos, cenários e postura estratégia; no estabelecimento das ações e dos resultados estratégicos através dos objetivos, metas, estratégias e políticas; na aplicação das decisões estratégicas com a definição dos projetos e planos de ações e, por fim, no acompanhamento, avaliação e aprimoramento do plano estratégico por meio da utilização de indicadores de desempenho e com melhoria contínua dos processos.

No intuito de aprimorar o planejamento estratégico é que Kaplan e Norton (1997) propuseram a metodologia de gestão denominada balanced scorecard (BSC). O BSC trouxe como novidade o alinhamento da visão e da estratégia aos objetivos e medidas de desempenho das empresas. Segundo os autores, o alinhamento proporciona o gerenciamento de longo prazo, sem que haja descuido das atividades cotidianas. Esse deve ser organizado nas perspectivas financeira, cliente, processos internos/aprendizado e crescimento, sendo possível agregar outras em decorrência do setor que atua a empresa ou da estratégia adotada. 
Com relação às perspectivas, Silva (2009) propõe uma adaptação para as IES. Segundo o autor, deve-se partir do entendimento da missão e da responsabilidade focada no aluno, além da compreensão dos seus macroprocessos de ensino, pesquisa e extensão e dos subprocessos decorrentes. Goldszmidt (2003) salienta que, para não incorrer no erro de implantar um BSC “genérico", é necessário adaptar a metodologia à realidade da empresa.

De acordo com a lógica estabelecida pelo método de Kaplan e Norton (1997), um BSC deve possuir objetivos estratégicos que traduzam a visão de futuro da organização em relação à causa e ao efeito, e esses devem ser organizados de forma clara em um documento chamado mapa estratégico. Segundo Caprio e Rocha-Pinto (2008), esse mapa pode tornar-se um recurso raro para garantir vantagens competitivas às empresas que o utilizem.

Conforme Prieto et al. (2006), para a organização obter vantagens, através da implantação do BSC, necessitará possuir estrutura formal, perspectivas bem definidas e uma boa comunicação. A comunicação visa mostrar a todos os níveis da organização os temas estratégicos como o crescimento da empresa, a redução de riscos ou o aumento da produtividade (KAPLAN; NORTON, 1997).

O processo de scorecard necessita envolver todos os níveis da empresa, tendo início com a participação ativa da alta administração (KAPLAN; NORTON, 1997). Para Caprio e Rocha-Pinto (2008), a falta de patrocínio da alta administração pode inviabilizar a gestão baseada nessa ferramenta. Kaplan e Norton (1997) salientam que essa metodologia deve representar o pensamento das equipes executivas, sendo que necessitam estar plenamente engajadas no processo, de modo que possam chegar a um acordo quanto aos propósitos principais para orientar e definir objetivos e medidas, obter o consenso entre os participantes e estabelecer a estrutura para a gestão e a implantação.

Com relação à implantação do BSC, Galas e Forte (2005) consideram o papel das pessoas como crítico nesse processo, sendo que as equipes necessitam possuir habilidades de aprendizado estratégico contínuo. Segundo Kaplan e Norton (1997), essa busca pelo aprendizado estratégico pode ser um dos motivos para a implantação do BSC, além de necessidades como: ter um consenso sobre a visão estratégica; desenvolver a equipe executiva; comunicar a estratégia; estabelecer metas estratégicas; alinhar os recursos às iniciativas e sustentar os investimentos em ativos intelectuais e intangíveis. O processo de implantação do BSC se inicia com a formalização das metas de superação e o 
desenvolvimento do plano de ações, devendo objetivar a integração do scorecard à filosofia gerencial da empresa (KAPLAN; NORTON, 1997).

Para que a implantação do BSC seja bem sucedida, Norton e Kaplan (1997) consideram que as organizações necessitam focar nos recursos humanos, nos recursos financeiros, nas equipes executivas, na tecnologia da informação e nas unidades de negócio. Nesse aspecto, destacam também a importância de alinhar a organização à estratégia, ou seja, traduzir essa estratégia em termos operacionais. Segundo os autores, isso será possível através das lideranças executivas e com a conversão da estratégia em processos contínuos, de modo a transformá-la em tarefa de todos.

Prieto et al. (2006) salientam que o sucesso da implantação do BSC pode depender de fatores como: comprometimento da alta administração, abrangência das perspectivas, tradução da estratégia adotada, divisão de papeis e responsabilidades, frequência das discussões e a ferramenta de tecnologia da informação utilizada.

Rocha e Lavarda (2011) resumem em três os fatores que facilitam ou inibem a implantação do BSC nas organizações: a cultura organizacional, a preparação e motivação dos colaboradores e o empenho e envolvimento da alta administração.

\subsection{INDICADORES DE DESEMPENHO}

A construção do BSC também necessita contar com indicadores de desempenho para medir e acompanhar o sucesso de cada objetivo. Esses indicadores precisam de metas, com o nível de desempenho esperado ou a taxa de melhoria necessária (KAPLAN; NORTON, 1997). O estabelecimento dos indicadores de desempenho constitui um dos aspectos mais importantes dos processos de gestão estratégica, como o BSC (OLIVEIRA, 2007).

Conforme Kaplan e Norton (2004), o estabelecimento de indicadores no BSC deve partir da definição de metas de qualidade, desempenho, prazos e serviços. Esses indicadores necessitarão serem compatíveis com as perspectivas financeiras, clientes, processos internos e aprendizado. Para Rocha e Lavarda (2011), a existência de um PE, anterior ao BSC, faz com que a implantação dos sistemas de medição torne-se mais fácil, sendo que cada organização deverá ajustar os indicadores de forma que atenda as suas necessidades.

No meio acadêmico, a compatibilidade entre os indicadores e as perspectivas deve ser pensada de modo a refletir a realidade do setor. No que tangem ao financeiro, recomenda-se 
ter indicadores para acompanhar o crescimento dos cursos e a diminuição dos custos indiretos dos mesmos (SILVA, 2009).

Para Silva (2009), a perspectiva clientes - alunos para as IES - necessitará de uma proposta de indicadores direcionada para a qualidade percebida, para o relacionamento com os discentes e os egressos e para a marca da instituição, sendo essa última a grande estratégia da empresa. No que corresponde à perspectiva de processos internos, necessitará ocorrer a descrição do gerenciamento da instituição, dos alunos e egressos, da inovação, da regulamentação e dos docentes e técnicos-administrativos.

A perspectiva de aprendizado e crescimento deverá trazer a relação dos ativos intangíveis correspondentes aos capitais humano, de informações e organizacional (SILVA, 2009). Com relação aos indicadores intangíveis, Colauto e Beuren (2003) destacam que a maior dificuldade não está em criá-los, mas sim em interpretá-los, dessa forma, propuseram que esses sejam acompanhados sob a ótica do crescimento e renovação, eficiência e estabilidade.

Resumidamente, além dos indicadores financeiros tradicionais, as ações no BSC terão os seus resultados acompanhados por metas direcionadas aos clientes, aos processos internos, às inovações, aos funcionários e sistemas. Com isso, o acompanhamento manterá os indicadores de curto prazo, agregando as medidas de médio e longo prazo, para tentar projetar os resultados futuros (BRANDÃO et al., 2008). Conforme Kaplan e Norton (2004), o que é medido é conseguido, dessa forma, defendem que os sistemas de mensuração influenciam os comportamentos e os resultados nas empresas.

\subsection{CULTURAS ORGANIZACIONAIS}

Segundo Rocha e Castro (2008), uma das principais funcionalidades do BSC consiste em poder alinhar o comportamento em torno dos objetivos fundamentais da organização. Dessa forma, se faz necessário entender a cultura organizacional para compreender e aperfeiçoar o processo de decisão e possibilitar a implantação de novas metodologias.

Conforme Engel, Blackwell e Miniard (2000), cultura consiste no conjunto de valores, ideias, artefatos e demais símbolos que possibilitam a comunicação, interpretação e avaliação dos indivíduos como membros de uma sociedade. Mowen e Minor (2003) definem cultura como o modo de vida das pessoas, que é aprendido e transmitido de geração para geração. Segundo os autores, é o que concede regularidade às sociedades, definindo o que é correto, 
bom e importante. Engel, Blackwell e Miniard (2000) afirmam que a cultura influencia os produtos, a estrutura de consumo, a tomada de decisão e a comunicação.

As empresas por sua vez, possuem características que formam a cultura organizacional, que é definida por Schein (1999) como a soma de todas as certezas compartilhadas e tidas como corretas que um grupo aprendeu ao longo de sua história. Segundo o autor, a cultura está para um grupo como a personalidade ou caráter está para um indivíduo.

Diante disso, para tornar o processo de decisão nas IES o mais assertivo possível, se faz necessário o desenvolvimento de uma cultura estratégica. Essa deverá possibilitar a definição de indicadores confiáveis, metas e objetivos claros, utilização de sistemas de informação para apoio a decisão, tarefas centradas nos processos e sinergia entre o que é acadêmico e o que é administrativo (BRAGA; MONTEIRO. 2005).

\subsection{CONTROLE E ACOMPANHAMENTO ESTRATÉGICO}

Conforme Oliveira (2007), o controle estratégico consiste no acompanhamento e avaliação dos resultados do planejamento estratégico. Esse acompanhamento deve comparar as situações alcançadas em relação às previstas, medindo e avaliando o desempenho das ações com relação às metas e objetivos estabelecidos. Com isso, os tomadores de decisões poderão corrigir e reforçar o processo estratégico, para que se possam alcançar os resultados esperados.

O processo de controle estratégico pode ser espontâneo e em tempo real, o que é denominado autocontrole (OLIVEIRA, 2007). Segundo Caprio e Rocha-Pinto (2008), esse acompanhamento se inicia logo após a implantação do $\mathrm{PE} / \mathrm{BSC}$, quando passa a ocorrer o monitoramento do desempenho da organização através da observação dos resultados, análises, reflexão e formulação de novas hipóteses.

Para Kaplan e Norton (2000), o desempenho das organizações necessita ser monitorado para que, através do feedback, se possa definir se as estratégias adotadas continuarão válidas ao longo do processo. Segundo os autores, as organizações focalizadas na estratégia concentram os seus esforços na melhoria da gestão e no aprendizado contínuo dos temas estratégicos organizado no BSC, de modo que a implantação dessa metodologia seja eficaz. 


\section{MÉTODO DE PESQUISA}

Essa pesquisa possui natureza qualitativa com o intuito de gerar conhecimento sobre o processo de implantação do BSC em uma instituição de ensino superior. Para tanto, se utilizou o método exploratório, por meio de entrevista em profundidade com roteiro semiestruturado. Conforme Malhotra (2006), a pesquisa qualitativa proporciona melhor visão e compreensão do problema, uma vez que se está diante de uma situação de incertezas.

Para Virgillito (2010), o objetivo desse tipo de pesquisa é identificar as opiniões dos indivíduos, visando entender as associações que fazem entre suas idéias e os aspectos investigados. Em conformidade com os autores, optou-se pela pesquisa exploratória por ser necessário definir o problema com maior precisão, identificando caminhos relevantes e obter dados adicionais.

$\mathrm{Na}$ universidade em questão, esse é o segundo plano estratégico formal que é implantado e o primeiro que utiliza a metodologia do BSC. Seguindo o que recomendam Kaplan e Norton (1997), as perspectivas foram adaptadas à realidade do setor, sendo organizadas em cinco: pessoas e gestão, processos internos, qualidade e relacionamento, alunos e sociedade e sustentabilidade, que se desdobraram em dezesseis objetivos e setenta e quatro projetos. Desses projetos vinte e cinco chegam ao nível das unidades acadêmicas (UAs), que passaram a construir os seus planos de ações de modo a contribuir com as PróReitorias e com a instituição como um todo.

Em virtude da estruturação descrita, a amostra foi composta por oito gestores que foram os responsáveis pela disseminação da nova metodologia nas Pró-reitoras em que atuam e nas faculdades. Dessa forma, a amostra utilizada é a não probabilística por julgamento, definida por Malhotra (2006) como uma forma de amostragem em que os elementos da população são escolhidos de acordo com os critérios do pesquisador. Conforme o autor, esse tipo de amostragem possui como limitação o fato de não se poder realizar generalizações, por ser pequena e não representativa.

Em conformidade com o que expõe Malhotra (2006), as entrevistas realizadas tiverem como procedimento a abordagem direta, pois o objetivo do estudo foi revelado aos respondentes logo no início. Para tanto, utilizou-se a técnica da entrevista em profundidade, que se consistiu em conversas utilizando um roteiro semiestruturado, em que todos os participantes foram indagados sobre os mesmos tópicos, em situações individuais. Seguindo as recomendações éticas do autor, essas entrevistas tiveram as gravações consentidas pelos 
participantes e duração média de quarenta e cinco minutos, totalizando cinco horas e quarenta e cinco minutos de gravações.

Com base na teoria e nos dados secundários apresentados, o roteiro semiestruturado discorreu sobre a importância do planejamento estratégico para as IES; importância de a estratégia estar alinhada ao operacional; importância do alinhamento entre objetivos, estratégias, projetos, ações e indicadores; cultura organizacional; equipes de trabalho; ferramenta de tecnologia da informação adotada; envolvimento dos líderes maiores da organização; indicadores de desempenho e acompanhamento, reflexão e aprendizado estratégico na instituição.

A metodologia de análise de dados iniciou com a transcrição na íntegra de todas as entrevistas. Conforme Virgillito (2010), a transcrição deve ocorrer de maneira rigorosa e fiel ao discurso do respondente para que o texto traga todas as suas verbalizações. Após transcrição foram procurados nos textos os aspectos positivos, negativos, influencias culturais, exemplos, sugestões e desafios apontados pelos entrevistados quando questionado sobre cada uma das questões. Conforme comentado anteriormente, a análise de dados se deu a partir da teoria e dos dados secundários.

Dessa forma, essa pesquisa foi aplicada após dois anos do início do processo de desdobramento do planejamento estratégico, com a utilização da metodologia de BSC, para todas as unidades acadêmicas da universidade. Conforme McDaniel e Gates (2003), com as verificações encontradas a partir dessa pesquisa poderão ser gerados dados secundários para pesquisas futuras, sendo que essas informações possibilitarão ajudar a esclarecer, redefinir e solucionar problemas, além de alertar para dificuldades em potencial.

\section{ANÁLISES DOS RESULTADOS}

A análise dos resultados está organizada de acordo com o roteiro semiestruturado que orientou as entrevistas, sendo dividia em nove tópicos.

\subsection{IMPORTÂNCIAS DO PLANEJAMENTO ESTRATÉGICO PARA AS IES}

Conforme recomenda Malhotra (2006), as entrevistas em profundidade devem ser iniciadas com questões abrangentes, sendo assim, se partiu da importância do planejamento estratégico (PE) para as Instituições de Ensino Superior (IES). 
Ao analisar os depoimentos, percebe-se que o reconhecimento dessa importância se constituiu uma unanimidade. Os entrevistados consideraram o PE fundamental por organizar as ações, envolver mais as pessoas, proporcionar aprendizado em sua elaboração e implantação, estimular a reflexão sobre o que se está fazendo e nortear aonde se quer chegar. Esses depoimentos vão ao encontro do que dizem Braga e Monteiro (2005), ao afirmarem que o planejamento estratégico deve produzir respostas consistentes para as questões: Onde estamos? A onde queremos chegar? Como vamos chegar?

Em concordância com o exposto, registra-se o relatado de um entrevistado que destacou que "principalmente na última década, as universidades perceberam que precisam ter uma gestão profissional e uma gestão das suas informações para a tomada de decisões, e o PE vem contribuir nesse sentido". Depoimento que encontra respaldo na afirmação de Braga e Monteiro (2005) de que o PE tem como objetivo direcionar e dar sustentabilidade para as instituições, mesmo em condições adversas.

$\mathrm{Na}$ mesma linha de pensamento, ao indagar os entrevistados sobre a importância do PE na Universidade em que atuam, foi destacada a sua relevância para consolidar a gestão de qualidade que presa historicamente a Instituição. Nesse caso, o desafio será aperfeiçoar os processos de gestão de forma que o planejamento chegue à base da administração.

\subsection{IMPORTÂNCIAS DE A ESTRATÉGIA ESTAR ALINHADA AO OPERACIONAL}

A importância que Kaplan e Norton (1997) dão para o alinhamento do planejamento estratégico às atividades operacionais da empresa é apontada como um desafio pelos entrevistados, isso por quê: "às vezes ainda andam meio em paralelo, agora vamos falar de estratégico, agora vamos falar de operacional". Para Kaplan e Norton (1997), o alinhamento proposto no BSC deve permitir o gerenciamento de longo prazo sem que haja descuido das atividades cotidianas. Segundo os autores, esse tipo de alinhamento é possível através do equilíbrio entre as medidas de resultado, que são consequências das atividades passadas, com as medidas que determinam o desempenho futuro.

Conforme os entrevistados, para o alinhamento ocorrer de uma forma mais efetiva, será necessária a integração do sistema de PE/BSC aos demais utilizados na Universidade e, principalmente, a integração ao sistema de orçamento. Os respondentes também apresentaram como oportunidade de ganho a possibilidade de tornar a comunicação mais intensa. Visto que 
a disseminação do BSC, a todos os níveis da organização, permitirá atingir o princípio de "tornar a estratégia tarefa de todos" (KAPLAN; NORTON, 1997).

\subsection{IMPORTÂNCIAS DO ALINHAMENTO ENTRE OBJETIVOS, ESTRATÉGIAS, PROJETOS, AÇÕES E INDICADORES}

Para avaliar como estão ocorrendo os alinhamentos entre os objetivos, estratégias, projetos, ações e indicadores os entrevistados foram questionados sobre: se acreditavam na existência de uma visão estratégica comum entre os diversos setores; se as prioridades institucionais foram bem definidas; se acreditavam na existência de um foco comum e sobre como avaliavam os desdobramentos que chegaram até o nível operacional.

A metodologia de BSC, introduzida por Kaplan e Norton (1997), trouxe a possibilidade de alinhar a visão e a estratégia aos objetivos e medidas de desempenho das empresas. Segundo Rocha e Castro (2008), para a grande maioria das empresas uma das principais funcionalidades do BSC consiste em poder alinhar o comportamento em torno dos objetivos fundamentais da organização. Ao analisar as entrevistas, percebe-se que essa é uma preocupação dos representantes das Pró-Reitorias, segundo eles, "têm objetivos estratégicos bem definidos", mas algumas ações poderiam ficar melhor alinhadas se isso ocorresse aos grandes projetos e não aos setores, o que acontece devido à forma de funcionamento da Instituição, justificam.

Com relação à existência de uma visão estratégica comum, a maioria dos depoentes entende como natural certo desalinhamento, pois a implantação do BSC ocorreu primeira nas Pró-Reitorias e após nas UAs. Conforme a declaração de que "a caminhada nas UAs foi posterior a nossa, então acho que eles estão passando por um processo de entendimento que nós também passamos". Segundo os entrevistados, o importante é que se está buscando esse senso comum, esse amadurecimento.

Cabe lembrar que a proposta do BSC é justamente realizar o alinhamento da visão e da estratégia aos objetivos e medidas de desempenho das empresas, traduzindo a visão de futuro da organização (KAPLAN; NORTON, 1997). Dessa forma, a compreensão dessa visão estratégica, deve ser um objetivo perseguido na implantação do BSC. Nesse aspecto é que existe possibilidade de melhoria, pois a assimilação dessa visão deverá trazer um engajamento maior por parte das equipes executoras, ao entenderem o seu papel no processo.

No propósito de entender os alinhamentos existentes e necessários para a organização é que se questionou sobre a definição das prioridades institucionais. Segundo os respondentes 
as prioridades - pessoas e gestão, processos internos, qualidade e relacionamento, alunos e sociedade e sustentabilidade - "são claras, foram bem definidas, são abrangentes e estão na fala das pessoas"; "elas conseguem dar conta da missão da instituição, com foco principalmente ligado ao aluno, respondendo aquilo que a instituição está propondo e disposta a alcançar".

Para finalizar a questão do alinhamento, foram avaliados os projetos que são compartilhados entre Pró-Reitorias e Faculdades, os chamados desdobramentos operacionais. Com relação ao desdobramento, os entrevistados manifestaram que os projetos que chegaram até o nível operacional eram os possíveis naquele momento, em que se estava iniciando o processo e procurando criar uma cultura estratégica na Instituição. Vale destacar o comentário de um entrevistado quando diz que "de alguma forma a gente deu conta do que é o foco da nossa Pró-reitora...".

Em decorrência do exposto, percebe-se que a IES tem buscado a consolidação dos alinhamentos através de perspectivas abrangentes, objetivos capazes de traduzirem a visão de futuro e projetos possíveis de serem executados pelas Pró-Reitorias e unidades acadêmicas. Desse modo, parece que a Instituição não incorreu no que Goldszmidt (2003) considera um erro comum, implantar um BSC "genérico", ou seja, sem realizar as adaptações necessárias à realidade da empresa. Além disso, o BSC acadêmico deve articular, operacionalizar e auxiliar no esclarecimento e na obtenção de consenso com relação ao que é estratégico na instituição (SILVA, 2009), o que parece ser decisivo para a eficácia do processo.

\subsection{CULTURAS ORGANIZACIONAIS}

Conforme Schein (1999), a cultura existente nas organizações impacta do cotidiano até a tomada de decisões. Ciente disso, é que se buscou entender como os representantes das Próreitoras percebiam a dimensão da cultura organizacional no processo de implementação da metodologia de BSC e como avaliavam essa relação.

Para os entrevistados as universidades possuem um o "jeito acadêmico de fazer as coisas, por que os professores são formados para a academia, mas não para a gestão, esse é o grande desafio", e isso influencia diretamente na implantação da metodologia, assim como a diferença entre as áreas de conhecimento, umas mais técnicas outras mais reflexivas, declaram. 
No entanto, os respondentes manifestaram "que de maneira geral a cultura contribuiu positivamente" para a implantação do PE/BSC na IES em questão. Segundo eles, a busca pela qualidade e excelência em ensino e pesquisa fez com que a Instituição à espera de uma ferramenta de gestão.

Diante disso, nota-se que, os entrevistados partilham do entendimento de que para fortalecer a tomada de decisões, é necessário desenvolver uma cultura estratégica, baseada em fatos e dados, é necessário estabelecer uma cultura voltada para a implantação, execução e controle da estratégia (BRAGA; MONTEIRO. 2005).

\subsection{EQUIPES DE TRABALHO}

Galas e Forte (2005) afirmam que as pessoas envolvidas na implantação do BSC possuem papéis críticos para o sucesso da metodologia. Dessa forma, entende-se como fundamental avaliar o papel e a atuação das equipes de implantação e execução do PE/BSC na Universidade.

Inicialmente, buscou-se entender como os entrevistados avaliavam a equipe de implantação da nova metodologia. Os depoimentos permitiram considerar que os membros da referida equipe estariam cumprindo o seu papel de "articulador, de mobilizador, de organizar as pessoas dentro do processo, mostrando as vantagens de seguir esse método". O que pode ser visualizado em afirmações como "o papel foi importante para levar ao conhecimento do pessoal da execução esse novo método que a Universidade quer utilizar".

No entanto, alguns respondentes relataram que as equipes de implantação e de execução ainda estão em momentos diferentes. Segundo os entrevistados, ainda tem pessoas "que se envolveram por que tinham que cumprir a tarefa e não vêm isso como uma forma de gestão". Mas demonstraram acreditar que esse comportamento faz parte do processo e afirmaram que a busca pelo engajamento e compreensão do processo necessita ser uma constante na implantação do BSC. Pois esse consiste em uma metodologia gerencial em que a sua aplicação requer mudanças profundas e esforço significativo (GOLDSZMIDT, 2003).

Para Caprio e Rocha-Pinto (2008), as pessoas responsáveis por gerar os dados e acompanhar os projetos, necessitam enxergar os benefícios que seus esforços devem gerar para a empresa. Dessa forma, a organização poderá contar com a motivação e o engajamento das mesmas. 
Com relação às possíveis melhorias, os entrevistados acreditam que será necessário ampliar as equipes de execução e interligar os sistemas de planejamento e orçamento. Além disso, destacam que a equipe de implantação deve manter-se flexível diante das diversas realidades existentes na IES, pois o "avanço será gradativo".

\subsection{FERRAMENTA DE TECNOLOGIA DA INFORMAÇÃO ADOTADA}

Kaplan e Norton (1997) afirmam que a tecnologia da informação é um dos fatores determinantes para o sucesso da implantação do BSC. Diante disso, torna-se essencial compreender os benefícios e os desafios percebidos pelos os usuários na utilização do sistema adotado na Universidade.

Ao analisar os depoimentos, percebe-se que os usuários reconhecem as vantagens da ferramenta de tecnologia da informação utilizada pela IES na gestão do BSC. Os aspectos positivos ficaram evidentes em expressões como: "acho que o sistema foi fundamental para o entendimento da metodologia"; "o benefício é manter todo o histórico da Universidade em um único local seguro, para as pessoas que decidem tenham acesso".

No entanto, os respondentes manifestaram certa dificuldade com relação à complexidade da ferramenta adotada, talvez pelo grande número de dados que essa integra e relaciona, ponderaram. Além disso, revelaram que muitos dos gestores não costumam utilizar a ferramenta, delegando o preenchimento dos dados às pessoas mais familiarizadas com a tecnologia. Isso evidencia a necessidade de alguns ajustes no processo, o que, segundo os entrevistados, deverá ser adequado com o tempo, através do incentivo de sua utilização na de tomada de decisão.

Vale destacar que, segundo Prieto et al. (2006), já é de conhecimento que a implantação do BSC incorre no risco de ser visto como um projeto de sistemas, ou que a utilização da ferramenta ocorra apenas em reuniões, como template. Para os autores, a moderação adequada está na criação de comitês formais de gestão superior, para liderar o projeto e delegar poderes. Na Universidade em questão, esses comitês foram criados em cada uma das cinco Pró-Reitorias, além de uma comissão geral de acompanhamento, o que parece ter contribuído significativamente no processo de implantação do BSC.

Diante do exposto, os entrevistados demonstraram acreditar que a ampliação do uso da ferramenta deverá surgir das próprias reuniões que esses realizam com as unidades acadêmicas. Nesses momentos, ocorrem estímulos para que o sistema seja manuseado no 
cotidiano, de forma sistêmica, sendo demostradas as vantagens de se obter informações através dos indicadores e visualizar os planos de ações. Também manifestaram que, conforme registrado anteriormente, a própria integração entre os sistemas deverá impulsionar uma maior utilização da ferramenta de gestão.

\subsection{ENVOLVIMENTO DOS LÍDERES MAIORES DA ORGANIZAÇÃO}

Segundo Kaplan e Norton (1997), a alta administração deve participar ativamente do processo de implantação do BSC para garantir o sucesso do projeto. Com base na afirmação dos autores é que se questionou sobre a participação dos líderes maiores da organização.

Para os entrevistados, a participação da alta administração foi considerada ativa durante todo o processo. A gestão na Universidade ocorre através de um colegiado, em que participam o Reitor, Vice-Reitor, Pró-Reitores e Assessores. A coordenação do projeto ficou a cargo do Vice-Reitor, com orientação e acompanhamento do Reitor. O Coordenador faz parte Comissão de Planejamento Estratégico da IES, que realiza reuniões semanais para verificar o andamento do processo. Esse comprometimento é reconhecido em declarações como: "a Reitoria abraçou a ideia, e todo mundo sabia que seria difícil, que implantar planejamento em uma estrutura desse tamanho é complicado".

Dessa forma, as entrevistas demonstraram que a implantação do BSC não incorreu no erro apontado por Prieto et al. (2006), falta de comprometimento da alta administração. O que Caprio e Rocha-Pinto (2008) afirmam poder inviabilizar a gestão baseada nessa metodologia. Já que a alta administração é a única que possui o conhecimento e o poder para levar a diante o BSC, dando a esse a prioridade necessária (GOLDSZMIDT, 2003).

\subsection{INDICADORES DE DESEMPENHO}

Segundo Oliveira (2007), um dos aspectos mais importantes do processo de gestão estratégica é o estabelecimento dos indicadores de desempenho. Dessa forma, buscou-se entender qual a importância que os entrevistados davam aos indicadores.

A relevância dos indicadores de desempenho foi reconhecida pelos entrevistados em falas como: "acho fundamental, pois a possibilidade de pensar em metas e acompanhar os resultados é a forma que temos para verificar também aquilo que não está dando certo, o que pode ser revisto" e "olhar para indicadores é ver algo concreto, isso proporciona um olhar estratégico de médio e longo prazo, as pessoas precisam disso". 
É justamente esse olhar para frente o diferencial dos indicadores utilizados no BSC, pois essa metodologia agrega as medidas de médio e longo prazo, para tentar projetar os resultados futuros (BRANDÃO et al., 2008). Silva (2009) salienta ainda que, no meio acadêmico, os indicadores devem refletir a realidade do setor, referindo-se aos cursos, alunos, egressos, professores e técnico-administrativos.

Segundo os respondestes, na Universidade, se buscou estabelecer indicadores condizentes com a realidade da IES, mas ainda existe possibilidade de melhoria na definição e no acompanhamento desses. Relataram que já houve um amadurecimento, mas que ainda existem indicadores que não são exatamente estratégicos e áreas difíceis de serem medidas, com indicadores intangíveis.

Conforme Colauto e Beuren (2003) é mais complexo interpretar os indicadores intangíveis do que defini-los. Para facilitar a interpretação, os autores propuseram que esses indicadores sejam acompanhados sob a ótica do crescimento e renovação, eficiência e estabilidade.

De acordo com o exposto, os entrevistados demonstraram ter pleno conhecimento da importância de acompanhar os indicadores e da necessidade de disseminar essa ideia entre todos os membros da organização. Os mesmos evidenciaram que os processos de definição e acompanhamento necessitam ser aperfeiçoados, sugerindo que sejam revistos os períodos de medição de alguns indicadores e que ocorra a integração dos bancos de dados existentes.

\subsection{ACOMPANHAMENTO, REFLEXÃO E APRENDIZADO ESTRATÉGICO NA INSTITUIÇÃO}

Segundo Kaplan e Norton (2000), as organizações com foco na estratégia devem concentrar os seus esforços na melhoria da gestão e no aprendizado contínuo, por meio do processo de acompanhamento e reflexão sobre os temas estratégicos organizados no BSC. Por esse motivo, considerou-se importante avaliar como os entrevistados visualizam esse processo dentro da Universidade.

Com base nos relatos foi possível perceber que as Pró-Reitorias têm acompanhado os resultados dos seus indicadores e os das UAs, mas ainda não ocorreu a definição de uma sistemática de gestão capaz de tornar esse processo contínuo. Os entrevistados relataram que "necessita-se investir nessa mudança cultural”, pois, segundo eles, as UAs também devem compreender a importância desse processo e se habituarem a acompanhar os seus indicadores e planos de ações de uma forma ininterrupta, ao longo do semestre. 
$\mathrm{Na}$ Universidade, a busca pelo aprendizado e reflexão estratégica parece ser anterior ao BSC, mas "não em todas as áreas", como declarou um entrevistado. Segundo os respondentes, o amadurecimento da gestão estratégia vem se desenvolvendo ao longo desses dois anos e será efetivo quando "os gestores conseguirem olhar para os projetos sabendo que esses estão ali para melhorar aquela área, ou quando analisarem os resultados dos indicadores antes de tomarem decisões".

Desse modo, a metodologia introduzida por Kaplan e Norton parece estar proporcionando uma reflexão de forma mais sistematizada, nas áreas que já possuíam essa prática. Nas demais, o que transparece é um aprendizado sobre o que é estratégico, sobre a tomada de decisão estratégia e sobre a utilização da metodologia de BSC.

\section{CONSIDERAÇÕES FINAIS}

Conforme exposto anteriormente, o objetivo dessa pesquisa consistiu em avaliar os fatores críticos da implantação do balanced scorecard (BSC) em uma instituição de ensino superior (IES). Para tanto, teve-se como base os fatores apresentados na literatura por Kaplan e Norton (2000), Prieto et al (2006) e Rocha e Lavarda (2011).

Dessa forma, após analisar os depoimentos acredita-se que o ponto de partida da implantação da metodologia de BSC - em uma IES - deverá ser o entendimento da cultura organizacional. Pois essas organizações possuem características muito próprias, específicas do meio acadêmico em que os diferentes saberes provocam reações distintas frente à nova metodologia de gestão. Desse modo, pode-se deparar com gestores entusiasmados com novidade, enquanto outros terão mais dificuldade em se adaptarem ou até mesmo se mostraram resistentes a sua utilização. $\mathrm{O}$ entendimento desse multiculturalismo permitirá compreender que será necessário ter abordagens diferentes para atingir o mesmo objetivo nas diversas unidades acadêmicas.

Outro fator que parece preceder a implantação do BSC é o entendimento da importância do planejamento estratégico para as instituições de ensino superior. Isso por que, conforme colocaram os entrevistados, o PE é fundamental por nortear aonde se quer chegar e propiciar reflexão e aprendizado estratégico. Esse reconhecimento ficou explícito entre os participantes da pesquisa, o que é bastante positivo, pois isso facilita a implantação do BSC e os alinhamentos estratégicos necessários. 
Com relação à estratégia estar alinhada ao operacional, fica evidente como é delicado esse aspecto na implantação do BSC, e como é importante trabalhar esse ponto para que o estratégico e o operacional não sigam em paralelo. Os entrevistados demonstraram ter essa consciência e relatam ações realizadas para que as pessoas percebam a relação das atividades diárias com os projetos e objetivos estratégicos da instituição. Nessa questão, constata-se que a implantação do BSC - em IES - não difere das demais organizações, sendo esse um fator crítico que merece atenção.

Outro fator crítico apontado na literatura e avaliado nesse trabalho foi o alinhamento entre objetivos, estratégias, projetos, ações e indicadores. A construção desse entendimento partiu de questões sobre a definição das prioridades institucionais, a existência de foco e visão estratégica comum e sobre os projetos que chegaram até o nível mais operacional na IES.

As repostas aos questionamentos citados deixaram evidentes o quanto é necessário ter prioridades institucionais bem definidas, abrangentes e adaptadas à realidade da organização. Essa adaptação, que é descrita na literatura como fundamental, parece ser ainda mais importante quando se trata de instituições de ensino, pois essas têm a perspectiva alunos em vez de clientes, e com esse existe toda uma responsabilidade pela formação humana e profissional, o que inclusive aparece descrito na missão de muitas dessas instituições. Dessa forma, como já era de se esperar, o foco da IES está centrado no aluno.

Com relação à visão estratégica, parece que essa ainda necessita ser consolidada entre os membros da organização, o que, segundo os depoentes, ocorrerá com o tempo. Da mesma forma, ainda é necessário amadurecer o desdobramento dos projetos, pois muitos desses ficaram apenas no nível das Pró-Reitorias, não podendo ser desenvolvidas ações nas unidades acadêmicas. Esse fato é um indício de como é complexo implantar um planejamento estratégico alinhado ao BSC em organizações grandes, com diversas áreas de conhecimento, como é o caso das IES.

Essa complexidade necessita estar clara para a equipe de implantação, que irá se deparar com a resistência de pessoas com relação à nova metodologia e a utilização do sistema de TI. No entanto, parece que na Universidade, essa equipe tem conseguido administrar o processo de implantação através da descentralização e criação de grupos de gestores em cada uma das Pró-Reitorias, além de se manter aberta ao diálogo com as distintas categorias de usuários. Entretanto, nem toda a equipe de execução parece ter clareza quanto à importância da metodologia de gestão, mas os entrevistados acreditam que isso será superado 
através do trabalho intensivo que tem sido realizado com reuniões, grupos de trabalho e treinamentos.

Outro fator que tem contribuído para a disseminação da metodologia é o comprometimento da alta administração. O Coordenador do projeto de implantação é o ViceReitor, que possui participação ativa dentro do processo, realizando reuniões semanais de acompanhamento e transmitindo as informações ao Reitor, Pró-Reitores e Assessores nas reuniões de colegiado. Esse comprometimento foi reconhecido pelos entrevistados e encontra a sua importância destacada na literatura, dada a relevância do conhecimento da alta administração e poder decisório para levar o processo adiante.

Assim como a alta administração, todo o grupo de gestores vem trabalhando na definição, acompanhamento e aperfeiçoamento dos indicadores de desempenho. Os indicadores do meio acadêmico possuem características e necessidades específicas, que muitas vezes dificultam a sua definição e medição. Mas de forma geral, percebe-se que esses têm atendido à necessidade das áreas, estão alinhados às perspectivas do BSC e permitem o acompanhamento dos projetos e ações.

A ferramenta de tecnologia da informação de BSC, por sua vez, parece ter tido um papel importante nesse processo de acompanhamento dos indicadores, ações, projetos e objetivos. Segundo os entrevistados, ela tornou possível a utilização e o entendimento da metodologia. No entanto, parece que houve um estranhamento inicial em sua utilização, sendo que ainda ocorrem casos que necessitam ser superados.

Dessa forma, pode ser considerado como ponto forte, no processo de implantação do BSC na IES, o reconhecimento da importância do planejamento estratégico (PE) para as IES; a existência de um foco estratégico comum; a definição de prioridades institucionais abrangentes; a criação de uma equipe de implantação capaz de disseminar a metodologia do BSC; ter uma ferramenta da TI para apoiar o processo e ter a participação ativa da alta administração.

Por fim, parece que o BSC tem contribuído para o desenvolvimento do aprendizado contínuo e da reflexão estratégica através do acompanhamento das ações e indicadores. Mas esse acompanhamento ainda necessita ser organizado de forma sistemática. Além disso, foram apontados como desafios a maior apropriação da ferramenta pelos usuários; a integração do sistema de BSC aos demais utilizados pela Universidade e o aprofundamento da cultura de gestão estratégica de longo prazo. 


\section{REFERÊNCIAS BIBLIOGRAFICAS}

BRAGA, Ryon; MONTEIRO, Carlos. Planejamento Estratégico: sistêmico para instituições de ensino. São Paulo: Hoper, 2005. 243p.

BRANDÃO, Hugo Pena et al. Gestão de desempenho por competências: integrando a gestão por competências, o balanced scorecard e a avaliação 360 graus. Revista de Administração Pública, Rio de Janeiro, v. 42, n. 5, p. 875-898, set./out. 2008. Disponível em:

$<$ http://www.scielo.br/pdf/rap/v42n5/a04v42n5.pdf > . Acessado em: 20 nov. 2012.

CAPRIO, Gisele Resende Araujo Mello Del; ROCHA-PINTO, Sandra Regina da. Fatores críticos para a implementação do Balanced scorecard: uma visão dos consultores organizacionais. In: ENCONTRO ANUAL DA ASSOCIAÇÃO NACIONAL DOS PROGRAMAS DE PÓS-GRADUAÇÃO EM ADMINISTRAÇÃO, 32., 2008, Rio de Janeiro. Anais... Rio de Janeiro: ANPAD, 2008. Disponível em:

$<$ http://www.anpad.com.br/download pdf.php?cod_edicao trabalho $=8613 \&$ cod evento edic ao $=38>$. Acessado em: 15 nov. 2012.

COLAUTO, Romualdo Douglas; BEUREN, Ilse Maria. Proposta para avaliação da gestão do conhecimento em entidade filantrópica: o caso de uma organização hospitalar. Revista de Administração Contemporânea, Rio de Janeiro, v.7, n.4, p. 163-185, out./dez. 2003. Disponível em: < http://www.scielo.br/pdf/rac/v7n4/v7n4a09.pdf $>$ Acessado em: 21 nov. 2012.

GALAS, Eduardo Santos; FORTE, Sérgio Henrique Arruda Cavalcante. Fatores que interferem na implantação de um modelo de gestão estratégica baseado no Balanced scorecard: estudo de caso em uma instituição pública. Revista de Administração Mackenzie, São Paulo, v. 6, n. 2, p. 88-111, maio/ago. 2005. Disponível em: $<$ http://editorarevistas.mackenzie.br/index.php/RAM/article/view/74/74>. Acessado em: 20 nov. 2013.

GOLDSZMIDT. Rafael Guilherme Burstein. Uma revisão de literatura dos fatores críticos para a implementação e uso do balanced scorecard. In: ENCONTRO ANUAL DA ASSOCIAÇÃO NACIONAL DOS PROGRAMAS DE PÓS-GRADUAÇÃO EM ADMINISTRAÇÃO, 27., 2003, Atibaia. Anais... Rio de Janeiro: ANPAD, 2003. Disponível em: < www.anpad.org.br/diversos/trabalhos/EnANPAD/.../ESO2121.pdf > . Acessado em: 15 nov. 2012.

ENGEL, James F.; BLACKWELL, Roger D.; MINIARD, Paul W. Comportamento do Consumidor. 8. ed. Rio de Janeiro: LTC, 2000. 641 p.

KAPLAN, Robert S.; NORTON, David P. A estratégia em ação: balanced scorecard. 7. ed. Rio de Janeiro: Campus, 1997. 344 p.

. Organização orientada para a estratégia: como as empresas que adotam o balanced scorecard prosperam no novo ambiente. 2. ed. Rio de Janeiro: Campus, 2000. 411 p. 
Kaplan e Norton na prática. 3. ed. Rio de Janeiro: Campus, 2004. 126 p.

MALHOTRA, Naresh K.; Pesquisa de marketing: uma orientação aplicada. 4. ed. Porto Alegre: Bookman, 2006. 720p.

MCDANIEL, Carl; GATES, Roger. Pesquisa de Marketing. São Paulo: Thomson, 2003. $562 \mathrm{p}$.

MOWEN, John C; MINOR, Michael S. Comportamento do consumidor. São Paulo: Prentice Hall, 2003. 403p.

OLIVEIRA, Djalma de Pinho Rebouças de. Administração estratégica na prática: a competitividade para administrar o futuro das empresas. 5. ed. São Paulo: Atlas, 2007. 279p.

PRIETO, Vanderli Correia; PEREIRA, Fábio Luis Alves; CARVALHO, Marly Monteiro de; LAURINDO, Fernando José Barbin. Fatores Críticos na implantação do Balanced Scorecard. Gestão \& Produção, São Carlos, v. 13, n. 1, p.81-92, jan./abr. 2006. Disponível em: $<$ http://www.scielo.br/scielo.php?script=sci_arttext\&pid=S0104-

530X2006000100008\&lng=en\&nrm=iso $>$. Acessado em: 20 nov. 2013.

ROCHA, Irani; LAVARDA, Carlos Eduardo Facin. Retrospectiva bibliográfica sobre o balanced scorecard (bsc) como instrumento de planejamento e controle nas empresas.

Revista de Contabilidade do Mestrado em Ciências Contábeis da UERJ, Rio de Janeiro, v. 16, n. 1, p. 19-34, jan/abril, 2011. Disponível em:

<www.spell.org.br/documentos/download/55>. Acessado em: 31 out. 2013.

ROCHA, Joseilton Silveira da; CASTRO, Miguel Rivera. Balanced Scorecard (BSC): a experiência das grandes empresas chilenas do setor vinícola. In: Associação Nacional de Programas de Pós-Graduação em Contabilidade, 2., 2008, Salvador. Anais... Salvador: AMPCONT, 2008. CD-ROM.

SCHEIN, Edgar H. Cultura Organizacional e Liderança. 1. ed. São Paulo: Atlas, 1999. $413 p$.

SILVA, Renato. Balanced Scorecard - BSC Gestão do Ensino Superior: gestão profissionalizada e qualidade de ensino para instituições de ensino superior privado. 1. ed. Curitiba: Juruá, 2009. 186p.

SOUZA, Isa. Quem é o jovem da Classe C e como muda a foram de consumo. Exame.com, São Paulo, 19 jul. 2012. Disponível em:

$<$ http://exame.abril.com.br/marketing/noticias/quem-e-o-jovem-da-classe-c-e-como-muda-aforma-de-consumir>. Acessado em: $21 \mathrm{dez} .2013$.

VIRGILliTO, Salvatore Benito. Pesquisa de Marketing: uma abordagem quantitativa e qualitativa. São Paulo: Saraiva. 2010. 500p. 